\title{
Sobre el binomio libertad y seguridad en el derecho*
}

\author{
Luciano Parejo Alfonso"
}

Recibido: 15 de mayo de 2016 • Aprobado: 10 de junio de 2016

\section{Resumen}

El presente trabajo estudia la compleja relación entre dos piezas claves del Estado de derecho: la libertad y la seguridad. Examina, en particular, la influencia actual del concepto ampliado de seguridad sobre el derecho fundamental a la libertad personal desde la idea de que el futuro puede depararnos escenarios de riesgos y peligros completamente nuevos. Este concepto de seguridad apunta así a la reacción frente a los fenómenos mencionados. En definitiva, tal finalidad supone también la reconfiguración de las tareas estatales y se dirige, a su vez, a una nueva concepción del Estado con una clara incidencia en la idea de libertad y, por tanto, de la propia del Estado de derecho.

Para todo ello, en primer lugar, analiza el contenido constitucionalmente declarado del derecho de libertad y de la seguridad en el ordenamiento jurídico español para resaltar, en definitiva, que la libertad y la seguridad, en tanto bienes estrechamente imbricados, se inscriben en el orden jurídico cuya efectividad es misión del Estado,

^ El presente artículo es resultado de la producción académica generada por el convenio suscrito entre la Universidad Santo Tomás (sede Bogotá) y la Universidad Carlos III de Madrid. El proyecto de investigación al que se adscribe el presente artículo es "Los retos de la Constitución y la administración frente a la paz y la seguridad ciudadana”. DOI: http://dx.doi.org/10.15332/s1900-0448.2016.0045.05

"^ Doctor en Derecho por la Universidad Autónoma de Barcelona y Catedrático de Derecho Administrativo sucesivamente en las Universidades de La Laguna (1983), Alcalá de Henares (1989) y Carlos III de Madrid (desde 1990 hasta hoy). En esta última ha sido decano de la Facultad de Ciencias Sociales y Jurídicas, secretario general y vicerrector de Profesorado y Departamentos, así como también vicerrector de Coordinación. Actualmente es director del Instituto Pascual Madoz, del Territorio, Urbanismo y Medio Ambiente de la mencionada Universidad. Fue rector de la Universidad Internacional Menéndez Pelayo en 2005 y 2006. Correo electrónico: luciano@der-pu.uc3m.es 
lo que hace referencia a la tradicional relación entre libertad y utilidad común, la koinon griega, que pasa a Roma como bonum commune. De seguido, aborda justamente cómo ese binomio libertad-seguridad enlaza con el bien común. No por azar, lo justo políticamente -que se expresa en la ley (derecho)- produce libertad en la seguridad gracias a la homonoia o consenso sobre los aspectos básicos de la convivencia. De ahí la indisolubilidad de libertad y seguridad. A continuación, y como se indica más arriba, se adentra en el origen y desarrollo actual de los riesgos que afectan a esa tradicional relación entre libertad y libertad. Como prueba de todo lo anterior, se finaliza con la exposición de su aplicación a un ámbito concreto: el urbanismo, pues, en efecto, la situación actual y los riesgos que encierra pueden ilustrarse a su luz en tanto expresión espacial de la sociedad, del sistema político y económico-social.

Palabras claves: Estado de derecho, derechos y libertades fundamentales, interés general, libertad, seguridad.

\title{
ON THE BINOMIAL LIBERTY AND SECURITY IN LAW
}

\begin{abstract}
This paper examines the complex relationship between two key pieces of the rule of law, freedom and security. Examines, in particular, the current influence of the expanded concept of security on the fundamental right to personal freedom from the idea that the future might hold completely risk scenarios and new dangers. This concept of security points, so the reaction to the targeted phenomena and, ultimately, that purpose also involves the reconfiguration of state tasks and aims, in turn, to a new conception of the state with a clear impact on the idea of freedom and therefore the rule of law itself.

For all analyzes, first, the content constitutionally declared the right to freedom and security in the Spanish legal system and to highlight, ultimately, freedom and security, while you goods closely interwoven enroll in the legal order whose effectiveness is mission of the State. What refers to the traditional relationship between freedom and common good, the Greek koinon goes to Rome as bonum commune. Of followed, addresses, just as the freedom-security binomial linked to the common good. Well, not chance, just enough politically, expressed in Law (Law), produces freedom in safety due to homonoia or consensus on the basic
\end{abstract}


aspects of coexistence. Hence the indivisibility of freedom and security. Then, as indicated above, it delves into the origin and development of current risks affecting the traditional relationship between freedom and liberty. As proof of the above, it ends with the exhibition of its application to a particular field: urbanism. Well, in fact, the current situation and the risks involved can be illustrated by its light while spatial expression of society, the political and economic-social system.

Keywords: Rule of law, fundamental rights and freedoms, public interest, freedom, security.

\section{SOBRE O BINÔMIO LIBERDADE E SEGURANÇA NO DIREITO}

\section{Resumo}

Este artigo estuda a complexa relação entre dois aspectos chaves do Estado de direito: a liberdade e a segurança. Analisa, em particular, a influência atual do conceito ampliado de segurança sobre o direito fundamental a liberdade pessoal com a ideia de que o futuro pode deparar cenários de riscos e conflitos completamente novos. Este conceito de segurança orienta-se na reação aos fenômenos já mencionados. Em conclusão, essa finalidade supõe a reconfiguração das tarefas do Estado e orienta-se numa nova conceição do Estado com uma clara incidência na ideia de liberdade e, por tanto, da própria do Estado de direito.

Para isso, em primeiro lugar, analisa-se o conteúdo constitucionalmente estabelecido do direito de liberdade e segurança no ordenamento jurídico espanhol para resaltar, em definitiva, que a liberdade e a segurança, como bens intimamente relacionados, inserem-se na ordem jurídica cuja efetividade é missão do Estado, o que faz referência a tradicional relação entre liberdade e utilidade comum, koinon grega, que chega a Roma como bonum commune. Depois, aborda-se especificamente como esse binômio liberdade-segurança se conecta com o bem comum. Não por acaso, o justo politicamente - que se expressa na lei (direito) - produz liberdade na segurança devido à homonoia ou consenso sobre os aspectos básicos da convivência. Por isso a indissolubilidade de liberdade e segurança. Após, como se assinalou antes, adentra-se na origem e desenvolvimento atual dos riscos que afetam essa tradicional relação entre liberdade e a liberdade. Finaliza-se com a exposição de sua aplicação num âmbito concreto: o urbanismo, ora, a situação atual e os riscos 
que implica podem-se ilustrar como expressão espacial da sociedade, do sistema político e econômico-social.

Palavras-chave: Estado de direito, direitos e liberdades fundamentais, interesse geral, liberdade, segurança.

\section{Introducción}

En el artículo 17 de la Constitución española (en adelante CE), la libertad y la seguridad aparecen reconocidas ciertamente como derechos distintos, e incluso aparentemente contradictorios, pero claramente relacionados entre sí, estrechamente imbricados y, en realidad, complementarios, indisolubles el uno del otro. Esta última circunstancia se registra en la acepción positiva de libertad expuesta en la 22. ${ }^{\text {a }}$ edición del Diccionario de la lengua española de la Real Academia española $(\mathrm{RAE}, 2006)^{1}$ : la facultad de que se disfruta en naciones bien gobernadas para hacer y decir cuanto no se oponga a las leyes ni a las buenas costumbres. La ligazón al "buen gobierno" implica la seguridad, lo libre y exento de todo riesgo, peligro o daño, de suerte que puede decirse que la indispensable seguridad es condición de la libertad y que esta determina a aquélla.

Se trata, en todo caso, de dos derechos de igual consistencia y eficacia, de derechos fundamentales de la sección $1 .^{\text {a }}$ del título I, cuyo contenido goza de tutela judicial preferente y reforzada (con posibilidad, en último término, de amparo constitucional) y que cuenta con un núcleo esencial protegido frente a la acción del legislador ordinario, necesaria en virtud de reserva constitucional y que ha de producirse -a la hora del desarrollo directo- en forma de Ley Orgánica (arts. 53.1 y 2 y $81.1 \mathrm{CE}$ ). Pero su entronque con el orden constitucional de valores superiores ${ }^{2}$ no se corresponde enteramente con este idéntico tratamiento en tanto que derechos fundamentales, pues en dicho orden:

${ }^{1}$ En su 23. a edición (2014), la acepción que más se aproxima a la expuesta en el texto es la quinta: "En los sistemas democráticos, derecho de valor superior que asegura la libre determinación de las personas", siendo la primera la siguiente: "Facultad natural que tiene el hombre de obrar de una manera o de otra, y de no obrar, por lo que es responsable de sus actos".

${ }^{2}$ La quinta acepción de libertad en la actual edición (23.a) del Diccionario de la lengua española de la Real Academia de la Lengua (2014) alude a este entronque. Véase nota anterior. 
La libertad aparece expresamente consagrada como tal valor superior tanto en la caracterización del Estado constituido como en la determinación del fundamento mismo del orden político y la paz social y, por tanto, de las concretas libertades públicas luego proclamadas: arts. 1.1 y $10.1 \mathrm{CE}$.

En el plano de los principios propios de las notas caracterizadoras del Estado constituido, la libertad aparece significativa y expresamente junto con la igualdad, solo a propósito del deber jurídico de acción positiva impuesto al Estado por razón de su carácter social (lo que pone de relieve la relación con la seguridad en términos de orden mínimo preciso) [art. 9.2 CE], por más que los principios proclamados en el art. $9.3 \mathrm{CE}$ sean esenciales obviamente a todo sistema jurídico basado en la libertad.
La seguridad, por el contrario, solo implícitamente puede entenderse consagrada en el orden de valores superiores y el fundamento del orden político, concretamente mediante, de un lado, la justicia, entendida como bien común y, de otro, la paz social, entendida como comprensiva del orden público (mínimo de efectividad real $0<<$ normalidad $>>$ precisa para la efectividad misma del orden constitucional) aludido en los arts. 16 y $21.1 \mathrm{CE}$ (véanse las STC 33/82 y 66/85).

En este mismo plano de los principios, la seguridad encuentra una proclamación expresa entre los propios del Estado de derecho (art. 9.3 CE) siquiera sea bajo la forma más amplia de la seguridad jurídica.

Como derechos fundamentales, la libertad y la seguridad presentan una construcción jurídica ciertamente específica, pero equivalente:

1. El derecho a la libertad del art. 17 de la $\mathrm{CE}$ aparece como una más de las libertades públicas concretas (junto con la libertad-derecho a la vida, a la integridad física y moral, a la de residencia y circulación y otras) en que se manifiesta el bien jurídico superior de la libertad proclamado en el art. 10.1 de la $\mathrm{CE}$ en términos de libre desarrollo de la personalidad. En este sentido, no es otra cosa -como señala la doctrina constitucional- que la autodeterminación por obra de la voluntad personal de una conducta lícita. De ahí la dificultad de su determinación positiva, la cual ha provocado que, en general, los intentos de determinación, científicos y de la doctrina del Tribunal Constitucional desemboquen bien en formulaciones negativas, bien en la reducción del derecho a su expresión en garantías, es decir, al entendimiento de éste como derecho reaccional frente a la privación ilegítima de la libertad. Frente a lo uno y lo otro, pero especialmente a esta última reducción, reaccionó en su momento eficazmente el Prof. García Morillo (1995), quien sostuvo de modo convincente que, en definitiva, la libertad personal consagrada en el art. 17 de la $\mathrm{CE}$ comprende únicamente las actividades humanas de carácter físico no protegidas específicamente por otras libertades-derechos (como las de los arts. 15 y 19 de la CE), con las que no se confunde. De ahí el carácter primario y residual de la libertad personal, 
ya que abarca todas las manifestaciones de la libertad merecedoras de protección no cubiertas por derechos fundamentales autónomos. Por tanto, se está ante la expresión subjetivada y concretada en derecho fundamental del valor superior de la libertad, en la traducción en derecho del principio de que todo lo no prohibido está permitido, es decir, ante el derecho constitucional a disponer de la propia persona, a determinarse por la propia voluntad y actuar de acuerdo con ésta, salvo prohibición constitucionalmente legítima. Aunque de lo dicho parezca inferirse que el derecho a la libertad personal se limita a acotar un espacio puramente defensivo, resistente a toda incidencia negativa, limitadora o de privación por parte del poder público -con lo que la acción positiva de éste nada tiene que ver en la realización y efectividad de aquélla-, lo cierto es que en la compleja sociedad actual va adquiriendo progresiva consistencia positiva -en el sentido de conferir título para reclamar del poder público la acción que sea precisa para su real y plena efectividad, como ya prevé, de otro lado, el art. 9.2 CE-fundamentalmente por medio de su conexión con los bienes y valores constitucionalmente protegidos a título de principios rectores de la política social y económica de los poderes constituidos (los previstos en el capítulo 3. ${ }^{\circ}$ del título I de la norma fundamental), y ello en la medida en que tales bienes y valores pasen a formar parte del contenido constitucionalmente declarado de los derechos fundamentales y las libertades públicas. Ya la STC 13/1992 -y luego también las STC 16/1996 y 173/1998- puso de relieve la importancia de los servicios y las prestaciones sociales para los derechos subjetivos de libertad a los efectos de sostener que, si bien no están construidos directamente como derechos subjetivos, los contenidos del capítulo 3 o del título I de la CE otorgan soporte al ejercicio de la competencia atribuida a las instituciones generales por el artículo 149.1.1 de la CE para establecer las condiciones básicas que garanticen la igualdad de todos los españoles en el ejercicio de los derechos y en el cumplimiento de los deberes constitucionales. Y la STC 119/2001, de 24 de mayo, dio el salto decisivo a la afirmación del bien-valor "medio ambiente adecuado" (proclamado en el artículo $45 \mathrm{CE}$ ) como elemento componente del contenido de derechos típicos de libertad, por ejemplo, el derecho al honor, a la intimidad y a la inviolabilidad del domicilio; salto éste luego confirmado por la STC 135/2011, de 29 de septiembre.

2. También la seguridad a que se refiere el art. 17 de la $\mathrm{CE}$ tiene la condición de derecho fundamental-libertad pública. Aunque el Tribunal Constitucional 
ha señalado que ésta no se confunde con la seguridad jurídica a que se refiere el art. 9.3 de la $\mathrm{CE}$, es claro que ambas están relacionadas, estando la primera comprendida en la segunda, en cuanto ésta es una forma superior del valor de la seguridad, entendida como ausencia de perturbaciones procedentes de medidas arbitrarias. Así como la libertad se concreta en una pluralidad de libertades públicas específicas, también la seguridad jurídica guarda relación con diversas manifestaciones específicas del valor "seguridad", todas las cuales culminan y adquieren sentido, en definitiva, desde y en función de aquel principio general.

La seguridad como derecho y libertad se inscribe en el orden público al que alude la norma fundamental como límite de otros derechos fundamentales y libertades públicas (así los proclamados en los arts. 16 y 21 de la CE) y en la noción más amplia de "paz social" a que se refiere el art. 10.1 de la CE, desde la perspectiva de la libertad y el orden de los derechos inherentes a la persona. La seguridad es aquí equivalente al estado de normalidad mínima -en sentido material o real- preciso para la efectividad de los derechos y las libertades de la persona, lo que no significa que sea un concepto carente de sustancia jurídica ${ }^{3}$.

La seguridad y el orden público son, en efecto y al mismo tiempo, i) exigencias del orden jurídico - para su efectividad-y ii) consecuencia de ese orden jurídico - pues no hay ni puede haber otra seguridad que la derivable y justificable en el orden jurídico y, en último término, el orden constitucional mismo-. De ahí que la seguridad, precisamente junto con el libre ejercicio de los derechos y las libertades, sea tratada igualmente en la Constitución (art. 104.1) como responsabilidad, objetivo y resultado de la acción del poder público, concretamente del administrativo ${ }^{4}$. Hay aquí además una clara

\footnotetext{
${ }^{3}$ Según la STC 325/1994, del 12 de diciembre, "la Constitución utiliza la palabra 'seguridad' con la misma acepción medular, pero con distintos matices según el adjetivo que le sirva de pareja. Habla, por una parte, de la seguridad jurídica (art. 9 C. E.), uno de los principios cardinales del derecho, a la par del valor justicia. Hay otra seguridad, la que es soporte y compañera de la libertad personal (art. 17 C. E.), cuya esencia se pone desde antiguo en la tranquilidad de espíritu producida por la eliminación del miedo. Una y otra han sido perfiladas por el Tribunal Constitucional desde su STC 2/1981 hasta la STC 126/1987. Esta, a su vez, aparece conectada a la tercera especie, la seguridad pública (art. 149.1.29 C. E.), también llamada ciudadana, como equivalente a la tranquilidad en la calle. En definitiva, tal seguridad se bautizó ya en el pasado siglo con la rúbrica del 'orden público', que era concebido como la situación de normalidad en que se mantiene y vive un Estado cuando se desarrollan las diversas actividades colectivas sin que se produzcan perturbaciones o conflictos”.

${ }^{4}$ Sobre estas cuestiones, últimamente, por todos, Casino Rubio (2015).
} 
reconducción de la seguridad como normalidad real mínima a la seguridad jurídica: aquélla aparece como basamento del edificio coronado por ésta.

Precisamente porque la seguridad jurídica es un bien y un principio general de rango constitucional, la seguridad en sentido material (normalidad mínima precisa para la efectividad del orden jurídico) es un derecho subjetivo $y$, concretamente, fundamental, que, al igual que la libertad personal -a la que está íntimamente ligada-, remite a la exigibilidad de la correspondiente prestación por parte del poder público en forma de acción administrativa (policial) preventiva y, en su caso, represiva, precisa para su garantía. De lo anterior se sigue el error de la extendida consideración de la libertad como esencialmente refractaria a la incidencia de la acción administrativa 5 . De la interpretación conjunta de los artículos 97, 103, 104 y 149.1.29 de la CE resulta con claridad que la acción administrativa policial percute con normalidad en la libertad, pues sin aquélla -la acción preventiva constante para evitar que los riesgos y peligros de perturbación de la normalidad mínima se actualicen, y la acción represiva para lograr el restablecimiento de ésta- tal normalidad mínima, es decir, la seguridad personal real no puede existir $y$, por tanto, tampoco la seguridad jurídica, a la que proporciona su base última fáctica o real. En otras palabras: sin una acción policial eficaz o, lo que es lo mismo, productora de seguridad ciudadana de modo constante no puede darse el estado de normalidad mínima que es presupuesto e integra el ambiente preciso para la efectividad de la libertad.

En definitiva: la libertad y la seguridad, como bienes estrechamente imbricados, se inscriben en el orden jurídico cuya efectividad es misión del Estado. Esto se refiere a la tradicional relación entre libertad y utilidad común, la koinon griega que pasa a Roma como bonum commune ${ }^{6}$.

\footnotetext{
${ }^{5}$ Esta concepción explica las dificultades que el Tribunal Constitucional ha tenido siempre para explicar satisfactoriamente el encaje constitucional de todas aquellas formas de incidencia en la libertad personal menos intensas y que no alcanzan el grado de privación de la libertad física (STC 98/1986, de 10 de junio; 22/1988, de 18 de febrero; y 341/1993, de 18 de noviembre), o no tienen su origen en ninguna causa penal (STC 94/2003, de 19 de mayo; y 132/2010, de 2 de diciembre).

${ }^{6}$ Esta relación y la preocupación hoy por el riesgo de que la creciente demanda de seguridad se convierta en el ácido en el que terminan por disolverse los derechos y las libertades fundamentales están perfectamente resumidas en el preámbulo de la reciente Ley orgánica 4/2015, de 30 de marzo, de protección de la seguridad ciudadana, cuando advierte que "libertad y seguridad constituyen un binomio clave para el buen funcionamiento de una sociedad democrática avanzada, siendo la seguridad un instrumento al servicio de la garantía de derechos y libertades y no un fin en sí mismo”. De modo congruente, "cualquier incidencia o limitación en el ejercicio de las libertades ciudadanas por razones
} 


\section{E1 binomio libertad-seguridad y su relación tradicional con el bien común}

Lo justo políticamente, que se expresa en la ley (derecho), produce libertad en la seguridad gracias a la homonoia o consenso sobre los aspectos básicos de la convivencia. De ahí la indisolubilidad de libertad y seguridad.

Alcanzado este punto, parece pertinente un pequeño excurso en torno a esta tradicional relación entre derecho y ley gracias -en el mundo griego (Platón y Aristóteles) - a la idea de que la segunda responde a lo útil de modo común (to koine sympheron; el bonum commune luego de los romanos), de donde parece seguirse una específica caracterización de la relación entre la libertad y el bien común, pues, en principio, postula una acusada correlación entre libertad y bien privado, de tal manera que la libertad, como quiera que cada cual la imagine, debe experimentar siempre y necesariamente una determinada pérdida (limitaciones, sacrificio) al contacto con el bien común. La clave de esta decisiva cuestión la proporciona el concepto que de libertad tenía el mundo clásico: la libertad como autarquía.

La libertad-autarquía es primariamente autosatisfacción (estar consigo mismo) y, por tanto, autosuficiencia: la realización de actividades por sí mismas, precisamente por tratarse de actividades "buenas"; realización en la que eran discernibles diversas posibilidades y, por tanto, diferentes estadios en la conquista de cada vez mayor autarquía, hasta alcanzar el último y más pleno estadio, propio de la ciencia y la filosofía (de dónde la teoría como criterio de la autarquía).

La libertad se ofrece, pues, como un proceso de conquista de "libertades"-en el sentido de "liberaciones" respecto de limitaciones- que va desde el bios apolaustikos al bios theoretikos, pasando por el bios politikos. El estadio decisivo es el primero, pues en él se produce la liberación de aquello que más ocupa nuestra vida (situándonos fuera de la "buena" vida, haciéndonos dependientes), es decir, del trabajo, la técnica y la economía. Aunque estas actividades deban examinarse por separado para comprobar lo que en ellas hay de esclavitud o pérdida de libertad, cabe circunscribirse, al menos aquí, al problema central que plantean: el de la posesión. En la economía se trata fundamentalmente de posesión, y ello puede predicarse

de seguridad debe ampararse en el principio de legalidad y en el de proporcionalidad en [su] triple dimensión [...]". En suma, termina advirtiendo, estas ideas "son las que han inspirado la redacción de esta Ley, en un intento de hacer compatibles los derechos y las libertades de los ciudadanos con la injerencia estrictamente indispensable en los mismos para garantizar su seguridad, sin la cual su disfrute no sería ni real ni efectivo". 
también de la técnica (acumulación de objetos creados). En todas las actividades mencionadas, en efecto, estamos ocupados para producir algo, guiándonos por la idea y el fin de la posesión, que el hombre cree necesaria para su vida a pesar de tener que constatar una y otra vez que no necesita en realidad todo lo elaborado o creado, que, en realidad, va más allá del uso para fundarse en la posesión. E1 hombre, pues, padece el querer poseer más de lo que puede usar.

Aquí reside la primera liberación, que lo es de la posesión. La liberación se traduce en la igualación de bios y praxis gracias a la circunscripción al uso: se trata de la forma de vida que gira en torno al goce, la consistente no solo en querer poseer los objetos, sino precisamente en usarlos.

La segunda liberación se consigue así en la práctica de lo común y, por tanto, de la política. Se trata ahora de la vida de uso, pensamiento y práctica de lo común. Las cosas usadas, pensadas y hechas comunes se califican, por ello, como "bienes". Para Platón y Aristóteles hay tres clases de bienes: los externos, los corporales y los internos o espirituales (también políticos: justicia, amistad-solidaridad, valor). En la vida política se trata de estos bienes. La primera liberación conduce a la libertad para la política, en la que se buscan los bienes políticos a fin de alcanzar la vida realmente política, la polis. Praxis de lo común significa, pues, praxis de los bienes políticos, que implica el reconocimiento del correspondiente orden de valoresbienes, la observancia de dicho orden y la actuación conforme a éste.

Para Platón, lo decisivo es el reconocimiento de ese orden de los bienes, su apreciación y estimación según su rango, podríamos hoy decir "conforme con la dignidad del hombre", porque el hombre tiene tendencia a trastocar el orden, el rango de los bienes, para encaramar a la cúspide el de la posesión. Con ello pone en peligro la política, haciendo imposible la libertad para la praxis de lo común. Pero se crea también un claro peligro para la tercera y definitiva liberación, la que se alcanza en el bios theoretikos, vida en la que el sabio, verdadero hombre de Estado, realiza la praxis política como justicia.

En su obra tardía Nomoi, Platón, desconfiando del hombre, transfiere a la ley este papel del sabio. De aquí proceden la tradición del bien común (koinon) como ley y la idea de que la ley sirve al bien común, pero no porque reconozca derechos individuales, sino porque remite a lo justo políticamente (politikon dikaion), que es igual a lo justo por naturaleza en Aristóteles ${ }^{7}$.

${ }^{7} \mathrm{Si}$ en el diálogo sobre la politeia de Platón el bien común no es aún un valor de primer rango (los conceptos básicos son aún lo bueno, lo justo y la polis), en su obra tardía Nomoi aparece ya -bajo la 
Como en el hombre lo principal es el deseo, el apetito, se le vincula a la polis como comunidad humana esencial que porta la naturaleza del hombre y le otorga relativa satisfacción en la medida en que permite a aquél descubrir desde y en la vida política que debe colocarse límites. El reconocimiento de los límites es una perspectiva filosófica esencial a la que se atribuye la virtud fundamental de la medida y la moderación, virtud que se reconoce a todo hombre como condición necesaria de la vida.

forma de utilidad específica de una comunidad y en contraste con la de los individuos- como segunda mejor constitución (tó koinón), consistiendo lo bueno, en todo caso, en un ideal solo reconocible por unos pocos y escogidos hombres. Aristóteles (Ética a Nicómaco y Política) despoja ya lo bueno de estatus objetivo e idealista al interpretarlo desde el concepto de felicidad, entendida esta como la del hombre individual. Pero los conceptos de lo bueno, la felicidad y la justicia permanecen en su obra siendo los valores guía de la conducta humana y, con ello, de la comunidad política, experimentando el concepto de bien común cierta revalorización (la justicia engloba la legalidad, y las leyes pueden servir tanto al bien general como al de un grupo determinado) que se concreta en la política: el bien común sirve de criterio para distinguir las constituciones buenas de las que no lo son. De esta suerte, pasa a primer plano en las formas de gobierno la contraposición entre bien común y bien particular.

Aunque el pensamiento romano (Cicerón, De res publica) la justicia continúa siendo un valor superior, el bien común (el de la Civitas romana) pasa a un primer plano sea como res publica, salus communis o utilitatis communio.

Es el cristianismo el que cambia la perspectiva: el bienestar terrenal -sea del individuo, sea de la comunidad- desciende a la categoría de medio respecto de la salvación eterna. En Tomás de Aquino (Suma Teológica), el bonum commune define la ley y asume así una posición central de la jerarquía entre lex aeterna, lex naturalis, lex divina y lex humana, pero el bonum es más bien reflejo de la idea platónica de lo bueno presentado en términos cristianos de utilidad de la res publica. De lo que se trata en primer término, pues, no es del bien común de una comunidad terrenal, sino de la salvación individual y de la comunidad eterna con Dios. Sin embargo, paralelamente aparece la idea de la actuación política dirigida al bien común como virtud primaria del princeps, incrementándose en importancia al compás de la ampliación de los cometidos del poder político más allá de la impartición de la justicia y el mantenimiento de la paz, y pasa a comprender la dirección política de la comunidad, el buen gobierno y administración.

El pensamiento político de la Modernidad supera (en Maquiavelo, Hobbes, Locke, Rousseau y Kant) los conceptos e ideales antiguos y medievales de lo bueno, la felicidad y la justicia, lo que conduce en algunos casos, y sin perjuicio de las diferencias, a que el bien común adquiera -como ideal de la actuación política- una posición mucho más reforzada (Maquiavelo constituye la excepción, al rechazar la noción de bien común). Lo importante en cualquier caso es que la perspectiva pasa a ser subjetiva (como luce claramente en la volonté générale de Rousseau), señalando el giro en la filosofía política: lo bueno, la felicidad o la justicia dejan de determinarse por un orden objetivo (religioso trascedente o inmanente), tomando el individuo el relevo como fuente última de la normatividad. Solo los individuos pueden justificar, en última instancia, decisiones comunitarias y, con ello, el poder político. De ahí surge la cuestión decisiva de cómo cabe unificar las necesidades y los intereses de los individuos en el bien común. Las respuestas resultan ser diferentes, pero lo destacable es que el bien común alcanza, en cualquiera de sus variantes, una especial significación solo en los autores de pensamiento relativamente colectivista, como Hobbes y Rousseau, mientras que, en los pensadores liberales, como Locke y Kant (luego padres del moderno Estado liberal de derecho), prácticamente no juega ningún papel. 
Se llega así finalmente a la homonoia, la igualdad o unicidad y, por ello, unidad en la razón. Según Aristóteles, los hombres tienen las mismas ideas y percepciones, por eso están unidos en comunidad política. Platón llama a este fenómeno el bien común (koinon); lo común reside no solo en la ley, sino en la sintonía, que, a su vez, debe ser la razón de la ley.

En resumen:

- A la posesión, vista ciertamente como exigencia elemental del hombre, se le reserva un puesto bajo en la escala de bienes: pertenece al mundo de la "primera" liberación.

- La segunda libertad aparece justamente vinculada a la posesión, pues consiste en la limitación de ésta, que permite el desarrollo de la vida en la comunidad. Esa limitación es, en efecto, estrictamente precisa, ya que la posesión no solo divide, también aniquila la vida.

- La búsqueda de los bienes políticos (sabiduría y justicia) une a los hombres en el bien común (espíritu de la ley).

Esta referencia de la libertad a lo justo políticamente resulta ser una idea constante en el pensamiento occidental desde Grecia hasta hoy. Cabe recordar la famosa frase de Hegel, según la cual el sistema jurídico es la libertad realizada o concreta.

No puede sorprender, por ello, que la positivación que de la libertad se hace en la declaración francesa de derechos del hombre de 1789:

- circunscriba la justificación de las diferencias sociales entre los hombres, siempre iguales desde su nacimiento, al <<bien común〉> (art. 1,

- identifique en el daño <<a otro > el límite de la libertad (art. 4 y

- cifre en la existencia de una fuerza pública instituida para beneficio de todos (y no para utilidad de aquéllos a los que está confiada) la garantía de los derechos del hombre y del ciudadano (art. 12).

Parece oportuno recordar la vieja raigambre de esta concepción de la libertad. La palabra griega que designaba la libertad (eleutheria) significaba, en efecto, la pertenencia recíproca de las personas, la pertenencia, pues, a un pueblo (eleutheros), ya que el hombre se caracterizaba como tal por estar en una comunidad. Esta significación se transmite al término gótico Liut y al germánico Leut: se trata, por tanto, de palabras relativas a la "gente" con la misma raíz de eleutheria. Y esta raíz alude a la causa clásica de la libertad y de lo que ésta trata: la comunidad y la unidad (en la polis), pues se es libre porque se pertenece a la polis, en tanto que ésta 
nos proporciona la autarquía, es decir, la libertad de la autosuficiencia, y ésta es la libertad políticamente común, la que resulta de la comunidad y unidad de la polis.

Aún hoy en el ámbito lingüístico alemán Freibeit (libertad) guarda relación con Freund (amigo), lo que se manifiesta en el verbo freien (pedir en matrimonio). En el lenguaje gótico, frijon significaba amar y cuidar, preservar, proteger, respetar, tratar bien. Y el actual, Freund significa, en último término, que nos pertenecemos unos a otros, si no amándonos, al menos en términos de buena disposición recíproca en nuestra relación, no dañándonos, sino respetándonos.

Con la Declaración revolucionaria de los Derechos del Hombre, la libertad se convirtió en derecho de éste, con lo que pasó a definirse por relación al hombre, es decir, a cualquier otro y, en último término, a la comunidad de los hombres. La libertad del hombre se determina en la medida en que se acomoda y ajusta a la de sus semejantes y finalmente sociopolíticamente. Esto es lo que expresa cabalmente el citado artículo 1 de la Declaración.

Puede retenerse así -sin que ello implique afirmar que se sabe con certeza lo que sea el bien común o la utilidad común- que el derecho a la libertad significa que ésta puede ser ejercitada y garantizada en relación con otros y con el bien común. Esto se expresa explícitamente en el art. 10 de la CE, al que son reconducibles todas las libertades construidas constitucionalmente como derechos. La libertad se determina en este artículo por tres relaciones y límites: por el derecho de otros, el orden constitucional (el orden político) y la paz social (el orden social-público).

El orden político y la paz social remiten, desde luego, al bien común, puesto que uno y otra representan vinculaciones para cada uno de los hombres, en las que el hombre siempre depende -en su individualidad personal y circunstancia singular caracterizada por necesidades específicas- de la correspondencia con otros hombres, es decir, de una unidad que sobrepasa toda singularidad e individualidad, que es tan fundamental y que incluso debe unir lo contrapuesto y lo contradictorio. Los juristas hablamos en este sentido de la "unidad de la Constitución“, lo que es casi un pleonasmo, porque la Constitución siempre ha sido la referencia superior a la unidad, tiene el significado de unidad.

Por tanto, de la inicial Declaración de los Derechos Humanos y también de su positivación actual en nuestro orden constitucional deriva que la libertad puede significar, de un lado, bien privado, pero de otro lado no puede descuidar el bien común o contraponerse a éste, ir en su contra, lo que encuentra su manifestación primaria en la seguridad, en el orden mínimo efectivo que es preciso para la convivencia con 
arreglo al orden jurídico. De ahí deriva con naturalidad que el derecho es el puente entre la libertad y el bien común, el fiel que determina su mezcla justa. Y más aún, que es el derecho el que nos proporciona ante todo libertad, pero precisamente en el contexto de la relación entre ésta y el bien común, que tiene como contenido mínimo indispensable la seguridad real precisa para la efectividad del orden jurídico.

Por tanto, desde la Declaración inicial de los Derechos del Hombre existe libertad por y en el derecho. Y calificamos los derechos humanos como derechos de libertad, siendo los principales o centrales la vida, la libertad y la propiedad (según la formulación de Locke, pero también del Bill of Virginia). Esto quiere decir que en todos estos derechos se trata de la libertad, de formas de libertad, de libertades concretas. Pero, si bien todos los derechos del hombre lo son de libertad, la libertad se proclama de forma independiente. ¿Qué significa esto?

Siguiendo a Baruzzi (1990), puede decirse que todos los derechos humanos esenciales son ciertamente derechos de libertad, pero que la verdadera libertad consiste en el desarrollo que de ésta se ha hecho en la Modernidad: libertad para y en el derecho, finalmente conducente al derecho del hombre, una evolución de la libertad en la que aún nos encontramos, en la medida en que queremos ir de los derechos liberales a los derechos sociales. En ella se trata siempre del derecho (de la positivación de derechos), yendo desde la libertad para el derecho a la libertad en el derecho, en cuanto aquélla tiene que realizarse en éste. Es precisamente esto lo que expresa Hegel en su famosa frase, antes citada, de que el sistema jurídico es la libertad realizada o libertad concreta.

\section{Los riesgos que afectan al binomio libertad-seguridad, su origen y su desarrollo actual}

Ocurre, sin embargo, que desde el Renacimiento y ya claramente con Descartes y Kant, la libertad aparece referida a la dignidad humana, entendida como autonomía. La referencia es ahora el hombre.

La autonomía de los modernos responde, entonces, a una construcción distinta de la propia de la autarquía griega. Aunque Locke y la declaración norteamericana de derechos se refieran a tres bienes comparables con los clásicos (la vida, la libertad y la propiedad) éstos bienes luego fueron declarados derechos del hombre que, para dicho autor, están en su posesión. La Modernidad no recomienda al hombre "bienes" para una vida de autosuficiencia, sino que afirma que el hombre es poseedor 
de la libertad, la vida y la propiedad. Prima en ella, por tanto, la perspectiva de la posesión, que es la que va a determinar la autonomía.

Por más que en él no se emplee el concepto de autonomía, el camino hacia la afirmación de autonomía se inicia con el discurso de Pico della Mirandola (2010) sobre la dignidad del hombre, que hace residir en la absoluta libertad para la autodeterminación, en la que el hombre es su propio juez (arbiter), el constructor y hacedor del mundo (plastes et fictor), y alcanza su plenitud dándose sentido a sí mismo (animi sententia). No se conecta aquí con la tradición griega, que era perfectamente conocida, lo que guarda relación con la significación política, que en dicha tradición tenía el concepto de autonomía (hacia el interior: la legislación independiente; hacia el exterior: la independencia). La autonomía nueva va más allá, como se refleja en la introducción de la palabra a propósito de la religión y el derecho del hombre ${ }^{8}$.

De manera que la libertad moderna pasa a consistir en la autodeterminación del hombre para la posesión de sí mismo y del mundo como un todo, con los siguientes escalones:

- El hombre se comprende y declara como poseedor. Se percibe a sí mismo como ser dueño en los ámbitos de la vida, la libertad y la propiedad. El primer y decisivo paso es, pues, el de la libertad para la posesión, la libertad de declararse propietario

- La libertad para la posesión conduce a la libertad de la posesión en los tres indicados ámbitos. Aquí la determinación como poseedor significa, ante todo, que la posesión puede ser incrementada en todos los expresados ámbitos. Trata la libertad, pues, de más propiedad, pero también de más vida. Lo que ofrece la naturaleza no es suficiente y se mejora con aplicación de la ciencia y la técnica, que aportan no solo más, sino nuevos bienes de vida y que pretenden, como Descartes ya apuntaba, poseer la propia vida.

- La libertad, en consecuencia, de lo hacedero. La autonomía es la libertad omnicomprensiva de lo hacedero en el hombre mismo y en el mundo.

La clave radica, sin duda, en la razón de que Locke habla primero de posesión y luego de derecho: la pretensión de posesión se caracteriza por su continuo crecimiento. El derecho se torna así momento decisivo de la posesión, pues el

${ }^{8}$ En Franciscus Burgcardus, libelo de 1586: De autonomia, das ist con Freystellung mehrerlay Religion und Glauben; y D. J. Chr. Mayer, obra de 1782: Freyheit, Herrschaft und Eigentum sind die Grundrechte der Menschen; die Urquellen der Autonomie. 
derecho es el que proporciona la posesión, en cuanto asegura la posesión de la vida, la libertad y la propiedad. El derecho hace de una pretensión de posesión una verdadera pretensión de derecho. Con ello, el derecho se entiende también en el sentido propio de la posesión, pudiendo ser calificado como pretensión de posesión asegurada jurídicamente.

E1 Estado se funda y justifica exclusivamente, entonces, para asegurar la pretensión de posesión que recibe la denominación de derechos fundamentales del hombre. De este fundamento depende el hombre, pues el es la razón de la posesión de la libertad, la vida y la propiedad. La posesión se torna así paradójicamente en fundamento del hombre.

Solo la posesión jurídica hace de la posesión querida una tenencia asegurada y accionable. La libertad para y en la posesión se torna, en último término, en libertad para el derecho. La libertad se realiza, en este sentido, en el derecho. Ello no significa que la libertad así entendida aluda solo al bien privado, pues presenta relación también con el bien común, como luce hoy, por ejemplo, en el número 2 del artículo 33 de nuestra Constitución. La diferencia con el mundo clásico está empero en el rango que se otorga a la posesión. La orientación actual la proporciona no tanto el bien común como las posibilidades proporcionadas por el Estado de la ciencia y la técnica, con la consecuencia inevitable de una mezcla en la que ya no puede hablarse de jerarquía de bienes y valores. De esta situación resulta que la comunidad política no puede presidir ya indiscutiblemente los ámbitos de la vida, la propiedad y la libertad. Con la Modernidad se pierde definitivamente la claridad en el orden de los bienes y valores.

Esta circunstancia no ha podido dejar de influir en la constitucionalización de la libertad y las libertades desde el valor central del hombre y su dignidad y, por supuesto, también en la interpretación y aplicación del correspondiente orden constitucional.

La progresión desde los derechos civiles a los derechos políticos, los derechos sociales de participación y los derechos de ciudadanía ha sido posible hasta hoy sobre la base de la inserción de la libertad en el bien común-mediante el equilibrio de sus dimensiones de bien privado y bien público- y gracias a la creencia en el progreso sobre la razón -herencia de la ilustración- y, por tanto, en que la praxis política podía conducir a un estado de "justicia" cada vez mayor, con salto incluso desde las comunidades nacionales a la comunidad universal.

La evolución en tal sentido (en el de progreso continuo e indefinido) parece haberse detenido ya hoy o, cuando menos, amenazar con detenerse y quebrar como 
consecuencia de la entronización del riesgo generado por el propio hombre y no ya por la naturaleza -en términos que han llevado a la calificación por Beck (1998) de la sociedad actual justamente como la sociedad del riesgo-, la generalización de un estado de incertidumbre (con pérdida de la creencia en el progreso) y la preeminencia de la economía, que se desarrolla incidiendo en el tejido social en términos de una nueva devastadora "revolución creadora" y en cuyo planteamiento actual está implícita la pretensión de redefinición del orden de valores desde su propia lógica. Está en juego así la homonoia, el consenso o contrato social básico basado en el reconocimiento compartido de un orden de valores, su observancia y la actuación conforme a él. Y desde el punto de vista jurídico, el riesgo de una mutación constitucional silenciosa por mor de la mercantilización progresiva del campo social y el recorte, la degradación al plano de la mera administración y gestión del espacio político conduce, en lo que aquí interesa, a i) la subordinación de los contenidos constitucionales más ligados a la dignidad de la persona y, por tanto, a las exigencias sociales que derivan de ésta, a los contenidos propios del "orden constitucional económico", lo que vale decir a ii) el desequilibrio entre las dimensiones privada y colectiva de la libertad en favor de la primera. La causa de tal riesgo reside en una suerte de recaída de la posesión con degeneración del bios apolaustikos griego, la fragmentación social múltiple y la dilución de la solidaridad en favor de un individualismo que se legitima en la reputación de la actuación de cada uno según los propios fines como fórmula por sí sola eficaz para la producción, como resultado de un orden social justo.

La ganancia de la economía supone pérdida del espacio político como orden dotado de primacía sobre las restantes dimensiones de la vida e idóneo para perseguir lo justo políticamente, el bien común. Y supone también la recuperación de terreno por la libertad como bien privado (posesión) en detrimento de la libertad pública o política. Se explica así que el incremento de la importancia que también ha experimentado la seguridad lo sea exclusivamente de la seguridad en su sentido más estricto de seguridad personal y no de verdadera seguridad pública, lo que viene permitiendo justamente el desplazamiento por la acción privada de la pública, garante de la seguridad ciudadana. Al respecto, lo sorprendente de la situación española actual no es tanto que exista esa acción privada en materia de seguridad, sino que, no habiendo sido ésta objeto de proceso alguno de "privatización", se califique legalmente de "seguridad privada" y no de seguridad pública cumplida 
por sujetos privados, con autorización para ello y colaboradora de la cumplida por el poder público, como parece en todo caso más conforme con el orden constitucional.

Los últimos y más relevantes acontecimientos con incidencia en la evolución de la seguridad, como sucedió con el execrable ataque del 11 de septiembre de 2001, no han supuesto novedad o cambios verdaderos, más allá de volver a poner en primer plano la trascendencia de la acción preventiva para la garantía de un estado real de normalidad mínima como presupuesto para el desarrollo de la vida social. Lo destacable es que el resurgimiento de la exigencia de seguridad constituye una reacción frente al ataque al sistema, no en su dimensión político-jurídica, sino en su dimensión económica, la prueba es que la atención se ha centrado en las Torres Gemelas y no en el Pentágono. No se observa, pues, contribución alguna a la recuperación del espacio político o público (de la libertad política o de los ciudadanos), sino más bien una puesta al servicio de la conservación del sistema económico.

\section{El urbanismo: las manifestaciones espaciales actualizadoras de los riesgos analizados}

Creo que la situación actual y los riesgos que encierra pueden ilustrarse a la luz del urbanismo como expresión espacial de la sociedad, del sistema político y del económico-social porque en el urbanismo se vienen produciendo transformaciones en las que se manifiestan los fenómenos antes aludidos ${ }^{9}$.

La polis griega se corresponde con una clara primacía de lo público en la ciudad de la Antigüedad. La ciudad griega, y en buena medida también la romana, apenas conocía una esfera de privacidad asegurada; incluso la domus constituía un espacio en gran parte accesible a terceros. Esta preeminencia del espacio urbano público se conserva en la ciudad-burgo medieval.

El origen de la relevancia del espacio privado puede situarse en la privacidad de la "casa" (la vivienda) que reclama para sí, como propia de su forma de vida, la burguesía liberal en el siglo XIX, con lo que resulta fácilmente relacionable con la importancia de la "posesión" en el sistema liberal del primer capitalismo. La privacy se expande rápidamente desde Gran Bretaña y obtiene protección por el legislador. Implica un principio de segmentación, de "encapsulamiento", de división de la ciudad en unidades sociales y espaciales que procuran blindarse todo lo posible frente a influencias externas. Aparecen así, junto con la residencia, toda clase de espacios

\footnotetext{
${ }^{9}$ Véase al respecto Lichtenberger (2002).
} 
de "retiro": clubes, círculos aristocráticos y burgueses, cabarés y cafés reservados que cubren toda la ciudad como una red. Las clases poseedoras, a la que la "gente" suscita reparo, crean espacios propios incluso en las instalaciones públicas: nichos, palcos en los teatros, camarotes en los barcos, cabinas en los balnearios, etc.

Los conceptos de espacio público, semipúblico y privado no son fijos, sino evolutivos en su definición jurídica, en dependencia del sistema político y económicosocial, y pueden experimentar cambio incluso en el seno de un mismo sistema, evidenciando así la verosimilitud de la mutación constitucional silenciosa a la que antes se aludió. El proceso de incremento del espacio privado en detrimento del público, correlato de las transformaciones que está experimentando el binomio libertad-seguridad, es especialmente apreciable hoy en el urbanismo de los Estados Unidos de América, que constituye un claro referente en la medida de su decisiva influencia en el urbanismo europeo ${ }^{10}$. En dicho país están en curso, en efecto, tres espectaculares procesos:

1. El malling, cifrado en la extensión y dominancia de los complejos comerciales y de consumo "cerrados", constituye el primer paso, la primera frontera de la privatización de espacios-ámbitos tradicionalmente "ciudadanos". Se trata de proporcionar al ciudadano-consumidor espacios cerrados y privados, pero constitutivos de una miniciudad dotada de calles, comercios, locales de ocio y esparcimiento, etc.., aparte, por supuesto, de vigilancia privada y, por tanto, de una seguridad "reforzada" (superior a la seguridad pública o propia del espacio público, que queda así desvalorizada), que previene eficazmente la exposición a los riesgos inherentes a la ciudad propiamente dicha.

2. El gating representa un paso más en la privatización de la ciudad y, por tanto, del espacio público. Va desde los watched neighborhoods, es decir, de las urbanizaciones suburbiales "vigiladas", pasando por los common interest developments hasta los gated communities y los walled cities.

En su expresión primaria, el vallado o cercamiento (para seguridad) de un determinado espacio residencial, gating es ya tan común que, desbordando el mundo de las capas sociales acomodadas, ha alcanzado al public housing, aunque al parecer sin mucho éxito por la dificultad en este caso del mantenimiento de la vigilancia privada. En su manifestación más desarrollada, esta fórmula, ya muy extendida, garantiza la "separación” radical respecto

${ }^{10}$ Sobre esta realidad, véanse Ponce Solé (1999, pp. 329 y ss.) y Ponce Solé (2001, pp. 667 y ss.). 
del espacio de convivencia común o general y la convivencia solo con "iguales" (personas de las mismas características e intereses) en miniciudades residenciales acotadas y, en definitiva, la "segregación" de éstas del estatuto común del territorio, lo que vale decir también del ordenamiento territorial general. El fundamento lo proporciona, aparte de la instrumentalización de la potestad municipal de zonificación - para establecer, por ejemplo, tipologías edificatorias y unidades de aprovechamiento o parcelas de dimensiones tales que solo estén al alcance de segmentos sociales de determinado poder adquisitivo-, la autonomía privada, capaz, mediante el pacto de los "estatutos" de las correspondientes urbanizaciones y "ciudades" de promoción privada, de definir con toda precisión las características de los residentes (solteros; casados pero sin hijos; personas de la tercera edad) y de sus actividades, y de posibilitar la exclusión de las personas que no reúnan las exigidas y, en su caso, la expulsión de las que dejen de reunir alguna de ellas.

3. La combinación del gating con el malling, que ha venido en llamarse "privatopía", proporciona el último escalón por ahora en la conquista de terreno al espacio público. La "privatopía" no es otra cosa que el nuevo gueto segregado por la sociedad posindustrial diferenciada por estilos de vida (según poder adquisitivo). Responde, en efecto, al proceso de formación primaria del gueto, es decir, al propio de la autoexclusión de la ciudad general y la procura de la emancipación normativo-administrativa de ésta mediante "órganos locales privados". Y ello, incluso en el centro de las ciudades -donde la comunicación de los ámbitos residenciales "cercados" con los centros comerciales "cerrados" sobre sí mismos se lleva a cabo por medio de conexiones practicadas en las paredes medianeras de los edificios o conseguidas mediante pasarelas voladas sobre las vías públicas-, permite circular sin necesidad de salir del espacio confortable y hecho seguro por una especial y privada vigilancia, es decir, de aventurarse a la calle, a la plaza, al espacio público, en el que la mezcla con toda clase de personas, incluso marginales, es inevitable, con los riesgos que ello inevitablemente conlleva.

Los procesos así brevemente descritos, que están teniendo una indudable influencia en el urbanismo continental europeo, traducen, sin duda, el de merma progresiva, en extensión, sustancia e importancia, de la política en beneficio de la economía. Y reflejan perfectamente su consecuencia: la segregación espacial como fruto de la fragmentación social; la desigualdad en la seguridad (la mínima 
correspondiente al estado de normalidad indispensable para la convivencia) como resultado de la desigualdad socio-económica, y la inevitable desigualdad en la libertad por razón de la existente en el presupuesto mismo de la efectividad de ésta.

\section{Conclusiones}

La época demanda la revitalización del valor de la dignidad del hombre libre conforme y para el bien común. La dignidad del hombre es una magnitud única que no se puede fragmentar en dimensiones (política, económica, social, etc.). Por eso mismo, es igual o idéntica en todos los hombres y demanda hoy, para su total eficacia, la plena ciudadanía de todos, entendida ésta como participación real en la vida social integrada gracias a la solidaridad.

La postulada revalorización de la dignidad requiere de suyo una articulación equilibrada de libertad y seguridad, ambas en el sentido más pleno y amplio, en el seno de la unidad del orden constitucional y a tenor del orden de valores por el mismo establecido, justamente a partir de aquella dignidad.

\section{Referencias}

Baruzzi, A. (1990). Freiheit, Recht und Gemeinwohl. Darmstadt: Wissenschaftliche Buchgesellschaft.

Beck, U. (1998). La sociedad del riesgo. Hacia una nueva modernidad. España: Paidós Ibérica. . (2006a). La sociedad del riesgo global. España: Siglo XXI Editores . (2006b). La sociedad del riesgo: hacia una nueva Modernidad. España: Ediciones Paidós Ibérica.

. (2008). La sociedad del riesgo mundial: en busca de la seguridad perdida. España: Ediciones Paidós Ibérica.

Böckenförde, E. W. (1976). Staat, Gesellschaft, Freiheit. Studien zur Staatstheorie und zum Verfassungsrecht. Frankfurt: Ed. Suhrkamp.

Casino Rubio, M. (2015). Seguridad pública y Constitución. Madrid: Instituto García Oviedo-Tecnos.

Denninger, E. (2005). Recht in globaler Unordnung. Berliner: Ed. BWV.

García Morillo, J. (1995). El derecho a la libertad personal. Valencia: Ed. Tirant Lo Blanch. Lichtenberger, E. (2002). Die Stadt. Von der Polis zur Metropolis. Darmstadt: Wissenschaftliche Buchgesellschaft. 
Parejo Alfonso, L. (2008). Seguridad y policía de seguridad. Valencia: Ed. Tirant Lo Blanch. Pérez Luño, A. E. (1990). Seguridad jurídica y sistema cautelar. Alicante: Biblioteca virtual Miguel de Cervantes.

Pico della Mirandola, G. (2004 [1486]). Discurso sobre la dignidad del hombre (Traducción A. Ruiz Díaz). México: UNAM.

Pico della Mirandola, G. (2010). Relato el Génesos. Discurso sobre la dignidad del hombre Revista Digital Universitaria, 11(11). Recuperado de http://www.revista.unam.mx/ vol.11/num11/art102/art102.pdf

Ponce Solé, J. (1999). Segregación espacial, derecho urbanístico y jueces audaces en los Estados Unidos de América (Con algunas reflexiones sobre el Derecho español). Revista Española de Derecho Constitucional, 19(57), 329-354.

Ponce Solé, J. (2001). Derecho urbanístico y segregación espacial. Ciudad y territorio: Estudios territoriales, 130, 667-686. 